\title{
İntravenöz Katater Uygulamasında Kullanılan Kelebek Desenli Tespit Malzemesinin Çocukların Emosyonel ve Fizyolojik Göstergelerine Etkisi
}

\section{The Effect of Butterfly Patterned Securement Dressing Used in Intravenous Catheter Admin- istration on Children's Emotional and Physiological Indicators}

\author{
${ }^{1}$ Ezgi Gamze BURUNSUZ, ${ }^{2}$ Selmin KÖSE \\ ${ }^{1}$ Beylikdüzü Devlet Hastanesi, İstanbul, Turkey \\ ${ }^{2}$ Biruni Üniversitesi, Sağlık Bilimleri Fakültesi, Hemşirelik Bölümü, İstanbul, Turkey
}

Ezgi Gamze Burunsuz: https://orcid.org/0000-0002-6555-2012

Selmin Köse: https://orcid.org/0000-0003-4958-6228

ÖZ

Amaç: Bu araştırma intravenöz katater uygulamasında kullanılan tespit malzemesinin çocuğun emosyonel ve fizyolojik göstergelerine etkisini belirlemek amacıyla gerçekleştirildi.

Materyal ve Metot: Örneklemi 30 deney, 30 kontrol grubu olmak üzere toplam 5-6 yaş arası 60 çocuk oluşturdu. Veriler, Çocuk ve Ebeveyni Tanılama Formu, Çocuklarda Emosyonel Göstergeler Ölçeği, Vital Bulgu Değerlendirme Formu kullanılarak topland. Deney grubuna renklendirilmiş kelebek desenli, kontrol grubuna ise rutin bakımda kullanılan beyaz renk tespit malzemesi kullanıldi.

Bulgular: Çocukların işlem öncesi, sonrası birinci ve beşinci dakikadaki nabız değer ortalamaları deney grubunda daha düşüktü $(\mathrm{p}<0,05)$. Oksijen satürasyon değerleri gruplar arasında işlem öncesi ve sonrası beşinci dakikada fark yokken, işlem sonrası birinci dakikada kontrol grubunda daha yüksekti $(p<0,05)$. Deney grubunun emosyonel göstergeler ölçeği puan ortalamalarının, kontrol grubundan daha düşük olduğu $(p<0,05)$ ve çocukların daha az negatif emosyonel davranış gösterdiği belirlendi.

Sonuç: Renklendirilmiş kelebek desenli tespit malzemesi ile çocuğun dikkatinin başka yöne çekilmesi fizyolojik göstergelerden nabız değeri ve emosyonel göstergeler üzerinde olumlu etki yapmıştır. Renklendirilmiş desenli tespit malzemesinin çocuk servislerinde kullanımının yaygınlaştırılması önerilir.

Anahtar Kelimeler: Çocuk, dikkat dağıtma, emosyonel durum, intravenöz katater

\section{ABSTRACT}

Objective: This study aims to determine the effect of the securement dressing used in intravenous catheter on the emotional and physiological indicators of the child. Materials and Methods: The sample consisted of 60 children who aged between 5 and 6,30 experimental and 30 control groups. The data were collected using the Child and Parent Diagnosis Form, the Emotional Indicators Scale in Children, the Vital Signs Evaluation Form. Colored butterfly patterned dressing was used in the experimental group and white securement dressing was used in the control group.

Results: The heart rate mean values of the children at the 1 st and 5 th minutes of before and after administration were lower in the experimental group $(p<0.05)$. The oxygen saturation values were not different between the groups at the 5 th minutes before and after the administration but were higher in the control group at the 1st minute after the administration $(p<0.05)$. It was determined that the mean score of the emotional indicators scale of the experimental group was lower than the control group ( $p$ $<0.05$ ), and the children showed less negative emotional behavior.

Conclusion: Distracting the child's attention with colored butterfly patterned securement dressing had a positive effect on the heart rate, which is among the physiological indicators, and emotional indicators. It is recommended to expand the use of colored patterned dressing in children's services.

Keywords: Child; distraction; emotional state; intravenous catheterization
Sorumlu Yazar / Corresponding Author:

Selmin Köse

10. Y1l Caddesi Protokol Yolu No: 4534010 Topkapı / İstanbul, Türkiye

Tel: +90 5356217611

E-mail: selminkose@biruni.edu.tr
Yayın Bilgisi / Article Info:

Gönderi Tarihi/ Received: 16/10/2020

Kabul Tarihi/ Accepted: 16/11/2020

Online Yayın Tarihi/ Published: 30/12/2020

Atıf / Cited: Burunsuz EG ve Köse S. İntravenöz Katater Uygulamasında Kullanılan Kelebek Desenli Tespit Malzemesinin Çocukların Emosyonel ve Fizyolojik Göstergelerine Etkisi. Online Türk Sağllk Bilimleri Dergisi 2020;5(4):673-682. doi: 10.26453/ otjhs.811634 


\section{GÍRIŞ}

Okul öncesi dönem gelişimin en hızlı olduğu, kişiliğin temellerinin atıldığg ve çocuğun öğrenmeye açıldığı kritik bir dönemdir ${ }^{1} \mathrm{Bu}$ dönemde ani ve hızlı gelişen akut hastalıklar hastaneye yatmayı gerektirebilir. İlk hastane deneyimi çocukların algılarını olumlu ya da olumsuz yönde etkiler. ${ }^{2-4}$ Hastanede yatan çocuk ve ailesinin uyumu için tüm sağlık profesyonelleri içerisinde hemşirenin rolü ve sorumluluğu büyüktür. ${ }^{3,5}$ Hemşirenin, çocuğu işlemlere hazırlayabilmesi, uygun iletişim tekniklerini geliştirebilmesi için, her yaş grubundaki çocuğun bilişsel gelişim özelliklerini, endişelerini ve beklentilerini bilmesi gereklidir. ${ }^{3,6}$ İnvaziv girişimler, çocuk için travmatiktir ve stres oluşturan işlemlerdendir. İnvaziv girişimlerden periferal ven lümeni içine yerleştirilmesi işlemi olan periferik venöz kateter uygulaması hastanede tedavi gören çocuklarda sık kullanılan bir uygulamadir. ${ }^{6,7}$

Çocuklarda katater takma sırasında yaşanan zorluklar nedeni ile ilk uygulamada takılma başarısı yetişkinlere oranla daha düşüktür. ${ }^{8,9}$ Çocukların hareketli olması nedeniyle intravenöz katater yerleştirilmesinde kataterin tespiti ve tespit için seçilen malzeme ayrı bir önem taşır. Tespitin çepeçevre ve sıkı bir şekilde, elastik olmayan ve terlemeye izin vermeyen materyal ile yapılması cilt enflamasyonu ile sonuçlanabilmekte, bu durumda kateterin erken çekilmesine neden olabilmektedir. ${ }^{10,11}$ Bunun yanında intravenöz katater çocuğun genellikle yatışı sırasında ilk karşılaştığı işlem olması, kataterin ellerinde takılı olarak kalması, canlarını acitan bu materyali istememesi, onlarda korkuya neden olmaktadır. Çocukların dünyasına uygun olan renklendirilmiş kelebek desenli tespit malzemesi ile nonfarmakolojik yöntemlerden biri olan dikkatini başka yöne çekme onların olumsuz emosyonel duygu yaşamasını azaltacaktır. İnvaziv girişimler sırasında uygulanan dikkati başka yöne çekme tekniklerinin ağrıyı azalttığı, emosyonel ve fizyolojik göstergeler üzerine olumlu etkisi olduğunu gösteren çalışmalar mevcuttur. ${ }^{5,12-14,15,16}$

\section{MATERYAL VE METOT}

Biruni Üniversitesi Girişimsel Olmayan Araştırmalar Etik Kurulu'ndan etik kurul izni alındı (Tarih: 30.04.2019, karar no: 2019/28-01). Helsinki İnsan Hakları Bildirisi ile ilgili kılavuz ilkelerine uygun olarak ve çocukların ebeveynleri tarafindan bilgilendirilmiş onam formu alınarak araştırma yürütüldü.

Araştırmanın Amacı ve Tipi: Araştırma, IV katater uygulamasında kullanılan kelebek desenli tespit malzemesinin çocuğun emosyonel ve fizyolojik göstergelerine etkisini belirlemek amaciyla randomize kontrollü deneysel olarak gerçekleştirildi.

Araştırmanın Hipotezleri: $\mathrm{H}_{1}$ :IV katater uygulama sonrası kullanılan tespit malzemesinin, çocuğun emosyonel göstergeleri üzerinde etkisi vardır.

$\mathrm{H}_{2}$ :IV katater uygulama sonrası kullanılan tespit malzemesinin, çocuğun fizyolojik göstergeleri üzerine etkisi vardır.

Araştırmanın Yeri ve Zamanı: Araştırma, İstanbul'da bulunan bir Eğitim ve Araştırma Hastanesi'nde Mayıs 2019-Aralık 2019 tarihleri arasında gerçekleştirildi. Araştırmanın evrenini, araştırmanın yapıldı̆̆ 1 hastanenin çocuk servisinde yatan 360 çocuk oluşturdu. Araştırmada örneklemin gücü, G*Power 3.1 programı ile hesaplandı. I. Tip hata miktarı 0,05 , testin gücü 0,90 olacak şekilde minimal örneklem büyüklüğü toplam 58 çocuk olarak hesaplandı. Araştırma 30 deney, 30 kontrol grubu olmak üzere 5-6 yaş arası toplam 60 çocuk ile gerçekleştirildi. Araştırmada deney ve kontrol grubunun dağılımı randomizasyon kura yöntemiyle belirlendi. Kura yönteminde siyah renkli içi gözükmeyen bir torba içerisine 30 tane mavi 30 tane kırmızı renkte top konuldu. Grupları belirlemek için servis sorumlu hemşiresinden torbadan bir top çekmesi istendi. Çekilen top mavi ise çocuk deney grubuna, kırmızı ise kontrol grubuna dahil edildi.

Veri Toplama Araçları: Veriler, Tanılama Formu, Çocuklarda Emosyonel Göstergeler Ölçeği (ÇEGÖ), Vital Bulgu Formu, Pulseoksimetre Cihazı ve Desenli Tespit Malzemesi kullanılarak toplandi.

Tanılama Formu: Araştırmacı tarafindan literatürden yararlanılarak hazırlanan form, çocuğun ve ebeveynlerin sosyo-demografik özelliklerini içeren 8 sorudan oluşmaktadır. ${ }^{4,5,14,15}$

Çocuklarda Emosyonel Göstergeler Ölçeği: William ve Lopez tarafindan 2005 yılında geliştirilmiştir. Çocukların tıbbi işlemlere karşı gösterdikleri emosyonel göstergelerin objektif olarak tanımlanabilmesi için kullanılan, değerlendirilmesi ve uygulanması kolay bir ölçektir. ${ }^{14}$ Ölçekte yüz ifadesi, ses, aktivite, etkileşim ve işbirliği düzeyini gösteren beş parametre kullanılmaktadır. Ölçekten alınan puan en düşük beş, en yüksek 25'tir. Puanın yüksek olması, çocuğun daha fazla negatif emosyonel davranış gösterdiğini belirtir. Türkçe geçerlilik ve güvenilirlik çalışması Atak Meriç tarafından 2017 yılında yapılmış ve ölçek toplam puanının cronbach alpha katsay1s1 0,88 olarak belirtilmiştir. ${ }^{5} \mathrm{Bu}$ araştırmada cronbach alpha katsayısı 0,90 olarak belirlendi. 
Vital Bulgu Formu: Araştırmacı tarafindan oluşturulan bu form, çocukların nabız ve oksijen saturasyonu $\left(\mathrm{SpO}_{2}\right)$ değerlerinin kaydedildiği formdur.

Pulse Oksimetre: $\mathrm{SpO}_{2}$ ve nabız değerlerini ölçmek için parmak ucuna bağlanan kablolu bantlı sensörlü monitör kullanıldı.

Desenli Tespit Malzemesi: Klinikte kullanılan beyaz tespit malzemesinin üzerine kelebek deseni baskısı araştırmacılar tarafından matbaaya yaptırıldı. Desen seçimi için araştırma öncesi 10 çocuğa balon, araba ve kelebek resimleri gösterilerek görüşleri soruldu. Çocukların \%80'i kelebek desenini tercih ettiği için kelebek desenli tespit malzemesi kullanıld1 (Resim 1).

Uygulama: Uygulama öncesi ebeveyn ve çocuklara araştırma hakkında bilgi verildi ve yüz yüze görüşülerek tanılama formu dolduruldu. Servise yatış tanıları benzer olan, kateteri ilk uygulamada açılan ve daha önce hastane yatış deneyimi olmayan çocuklar araştırmaya dahil edildi. Çocuklara, işlem öncesinde pulse oksimetre cihazı takıldı. İntravenöz katater takma işlemi araştırmacı tarafından müdahale odasinda uygulandi. Deney grubuna IV kateter uygulama sonrası renklendirilmiş desenli, kontrol grubuna ise hastanede rutin olarak kullanılan düz, desensiz tespit malzemesi kullanıldı. Deney grubundaki çocuklara işlem öncesi kullanılacak tespit malzemesi tanıtılarak açıklama yapıldı. Her iki grubunun işlem öncesi, işlemden bir dakika ve işlemden beş dakika sonra olmak üzere üç kez $\mathrm{SpO}_{2}$ ve nabız değerleri kaydedildi. Katater tespit edildikten sonra çocuklara Emosyonel Göstergeler Ölçeği uygulandı.

Verilerin Değerlendirilmesi: Veriler SPSS 22.0 paket programında uygun istatistiksel yöntemlerle değerlendirildi. Tanımlayıcı istatistiksel yöntemler olarak sayı, yüzde, ortalama, standart sapma gibi değerler alındı. Değişkenler arasındaki ilişki için Pearson Ki Kare testi, gruplar arasında fiziksel parametreleri ve ÇEGÖ puanlarını karşılaştırmak için Independent $\mathrm{t}$ test kullanıldı. Grup içi tekrarlı ölçümler için ise Repeated Measures test, ölçümler arasındaki ilişkinin tespit edilmesi için Bonferroni test kullanıldı. Anlamlılık seviyesi olarak $\mathrm{p}<0,05$ kabul edildi.

\section{BULGULAR}

Deney grubundaki çocukların \%53,3'ünün, kontrol grubundaki çocukların ise \%50'sinin erkek olduğu belirlendi. Deney grubunda çocukların \%56,7'sinin kontrol grubunda çocukların ise \%50'sinin beş yaşında olduğu bulundu. Çocukların yaşı ve cinsiyeti açısından gruplar arasında istatistiksel olarak fark olmadığ 1 , değişkenlerin her iki grup için homojen dağılmakta olduğu görülmektedir $(p>0,05) \quad(\underline{T a b l o}$ 1).

Deney ve kontrol grubundaki çocukların gruplar arası işlem öncesi, işlemden bir ve beş dakika sonra nabız değer ortalamaları incelendiğinde; deney grubundaki çocukların nabız değeri ortalamalarının daha düşük olduğu ve aralarındaki farkın istatistiksel olarak anlamlı olduğu bulundu $(\mathrm{p}<0,05)$ (Șekil 1).

Deney ve kontrol grubundaki çocukların, işleminden bir dakika sonra SpO2 değer ortalamaları incelendiğinde; kontrol grubundaki çocukların $\mathrm{SpO} 2$ değer ortalamalarının deney grubundaki çocuklardan daha yüksek olduğu belirlendi $(p<0,05)$. Bununla birlikte gruplar arasında işlem öncesi ve beş dakika sonra SpO2 değer ortalamaları arasında fark olmadı ̆̆ı saptandi ( $\mathrm{p}>0,05)$ (Tablo 2).

Deney grubundaki çocukların ÇEGÖ puan ortalamalarının kontrol grubuna göre daha düşük olduğu ve aralarındaki farkın istatistiksel olarak anlamlı olduğu bulundu $(\mathrm{p}<0,05)(\underline{\text { Tablo } 3})$.

\section{TARTIŞMA VE SONUÇ}

Nonfarmakolojik yöntemler çocuğun kısa süreli işlemlerle baş etmesinde çocuk, aile ve sağlık çalışanlarına yardım eden ucuz ve etkin yöntemlerdir. Literatürde, invaziv işlemlerde nonfarmakolojik yöntemler kullanılarak dikkati başka yöne çekmenin çocuğun ağrı ve anksiyetesini azalttığı, fizyolojik ve emosyonel göstergeler üzerinde olumlu etki oluşturduğu bildirilmiştir. ${ }^{15-19}$

Deney grubundaki çocukların işlem öncesi ve sonrasındaki $\mathrm{SpO}_{2}$ değer ortalamasının birbirine yakın olduğu, kontrol grubunda ise $\mathrm{SpO}_{2}$ değer ortalamas1nın işlemden bir dakika sonra en yüksek seviyede olduğu belirlendi. Karaca (2019), 4-6 yaş arası çocuklarla damar yolu açma işlemine yönelik oluşan korku ve anksiyete üzerine müzikli-hareketli oyuncakların etkisini incelediği çalışmada, deney ve kontrol grubundaki çocukların damar yolu açma işlemi sırasında $\mathrm{SpO}_{2}$ değerleri arasında istatiksel olarak anlamlı bir fark olmadığını rapor etmiştir. ${ }^{20}$ Erbay $^{21}$ çalışmasında çocuk acil servisinde 2-7 yaş grubu çocuklarda periferik katater yerleştirme sırasında çizgi film izletmiş, nabız ve $\mathrm{SpO} 2$ değer ortalamalarının deney ve kontrol grubu arasında fark olmadığını belirtmiştir.

Deney grubundaki çocukların, kontrol grubundaki çocuklara göre işlem öncesi ve işlemden sonra ölçülen nabız değer ortalamalarının daha düşük olduğu, işlemden bir dakika sonra her iki grupta da en yüksek seviyede olduğu belirlendi. Nyguyen ve ark., 
lomber ponksiyon yapılacak 7-12 yaş arası çocuklarda müziğin ağrıya etkisini inceledikleri çalışmada, deney grubundaki çocukların nabız değerlerinin hem uygulama sırasında hem de sonrasında anlamlı şekilde düşük olduğunu belirtmişlerdir. ${ }^{22}$

Kelebek desenli tespit malzemesi uygulanan çocukların daha az negatif emosyonel davranış gösterdiği belirlendi. Araştırma sonuçlarına benzer şekilde He ve ark. ${ }^{15} 6-14$ yaş arasındaki çocukların preoperatif hazırlıklarında terapötik oyunun etkisini belirlemek amacı ile yaptıkları çalışmada deney grubundaki çocukların, daha az negatif emosyonel tepkiler gösterdiklerini bildirmişlerdir. Li ve ark. ${ }^{4}$ yaptığ $\breve{~ b i r ~}$ çalışmada, 3-7 yaş ve 8-12 yaş grubundaki çocukların hastaneye yatışta iki hastanede farklı uygulamalar gerçekleştirilmiş; bir hastanede çocukların hastaneye yatışı sırasında çeşitli terapötik oyunlar kullanılırken, diğer hastanedeki çocuklar kontrol grubunu oluşturmuştur. Çalışmada deney grubundaki çocukların kontrol gruplarına göre daha az negatif emosyonel tepki gösterdikleri bulunmuştur. ${ }^{4}$ Literatürde yer alan başka çalışmalarla, ağrılı tıbbi işlemler öncesi, sırası ve sonrasında nonfarmakolojik yöntemlerin kullanılmasının işlem sırasında oluşan negatif emosyonel tepkileri azaltmada etkili olduğu gösterilmiştir. ${ }^{4,5,14-15,17-19}$

Sonuç olarak, çocuklarda IV katater uygulama sonrası kullanılan renklendirilmiş desenli tespit malzemesinin emosyonel göstergeler ve fizyolojik göstergelerden nabız değerleri üzerine olumlu etkisi vardır. Çocuk servislerinde kullanımının yaygınlaştırılması önerilebilir.

Araştırma bulguları, tek bir çocuk servisi hastalarından elde edilen veriler ve kullanılan ÇEGÖ ölçeğinin ölçtüğü değerlerle sınırlı olması bu araştırmanın sinırlılıklarıdır.

Etik Komite Onayı: Biruni Üniversitesi Girişimsel Olmayan Araştırmalar Etik Kurulu'ndan etik kurul izni alındı (Tarih: 30.04.2019, karar no: 2019/2801).

Çıkar Çatışması: Yazarlar çıkar çatışması bildirmemişlerdir.

Yazar Katkılart: Fikir - EGB; Denetleme - SK; Malzemeler- EGB; Veri toplanması ve işlemesiEGB; Analiz ve/veya yorum - EGB, SK; Yazıyı yazan - EGB, SK.

Hakem değerlendirmesi: Dış bağımsız.

\section{KAYNAKLAR}

1. Arıkan D, Çelebioğlu A, Güdücü Tüfekci F. Çocukluk dönemlerinde büyüme ve gelişme.
İçinde: Conk Z, Başbakkal Z, Bal Yılmaz H, Bolışık B, eds. Pediatri Hemşireliği. 2. Baskı. Ankara: Akademisyen Kitabevi, 2018:53-66.

2. Kyle, T. Essentials of Pediatric Nursing. 2nd ed. Philadelphia: LWW Publishing; 2008.

3. Çavuşoğlu H. Hastaneye yatmanın çocuk ve aile üzerindeki etkileri. İçinde: Çavuşoğlu H, ed. Çocuk Sağlığı Hemşireliği. 10. baskı. Baskı Ankara: Sistem Ofset Basımevi, 2013:51-66.

4. Li WH, Chung JOK, Ho KY, Kwok BMC. Play interventions to reduce anxiety and negative emotions in hospitalized children. BMC Pediatrics. 2016;16(1):1-9. doi:10.1186/s12887-0160570-5

5. Atak Meriç T. Okul öncesi dönemdeki çocuklarda venöz kan alımı sırasında iki farklı oyuncakla yapılan dikkati başka yöne çekme işleminin çocuğun emosyonel ve fizyolojik göstergelerine etkisi. Yeditepe Üniversitesi Sağlık Bilimleri Enstitüsü Hemşirelik Anabilim Dalı, Yüksek Lisans Tezi. İstanbul, Türkiye. 2017.

6. Adams J, Motzhan A. Fluid-electrolyte acidbase balances. In: Potter PA, Perry AG, RossKerr AJ, Wood MJ eds. Canadian Fundementals of Nursing. Elsevier, Inc; 2016:1144-1208.

7. Rodriguez-Calero MA, Fernandez-Fernandez I, Molero-Ballester LJ, Matamalas-Massanet C. Risk factors for difficult peripheral venous cannulation in hospitalised patients. Protocol for a multicentre case-control study in 48 units of eight public hospitals in Spain. BMJ Open. 2018;8(2):1-6.

8. Rivera AM, Strauss KW, Van Zundert AAJ, Mortier EP. Matching the peripheral intravenous catheter to the individual patient. Acta Anaesth Belg. 2007;58(1):19-25.

9. Yen K, Riegert A, Gorelick MH. Derivation of the ZIVG score: a clinical prediction rule for the identification of children with difficult intravenous access. Pediatric Emergency Care. 2008;24(3):143-7. doi:10.1097/ PEC.0b013e3181666f32

10. Murayama R, Takahashi T, Tanabe H, et al. The relationship between the tip position of an indwelling venous catheter and the subcutaneous edema. Bioscience Trends. 2015;9(6):414-419.

11. Cihan Erdoğan B, Denat Y. Periferik intravenöz kateter komplikasyonlarından infiltrasyon ve hemşirelik bakımı. Hemşirelikte Eğitim ve Araştırma Dergisi. 2016;13(2):157-162. 
12. James J, Ghai S, Rao K, Sharma N. Effectiveness of animated cartoons as a distraction strategy on behavioural response to pain perception amond children undergoing venipuncture. Nursing and Midwifery Research Journal. 2012;8 (3):198-207.

13. Vagnoli L, Caprilli S, Vernucci C, Zagni S, Mugnai F, Messeri A. Can presence of a dog reduce pain and distress in children during venipuncture? Pain Manag Nurs. 2015;16(2):89-95. doi:10.1016/j.pmn.2014.04.004

14. William Li HC, Lopez V. Children's emotional manifestation scale: development and testing. Journal Clinical Journal. 2005;14(2):223-9. doi.org/10.1111/j.1365-2702.2004.01031.x

15. He HG, Zhu L, Chan SWC, et al. Therapeutic play intervention on children's perioperative anxiety, negative emotional manifestation and postoperative pain: a randomized controlled trial. Journal of Advanced Nursing. 2015;71 (5):1032-1043. doi:10.1111/jan.12608

16. McMurtry CM. Pediatri needle procedure: parent-child interactions, child fear, and evidencebased treatment. Canadian Psychology/ Psychologie Canadienne. 2013;54(1):75-79.

17. Özveren H. Ağrı kontrolünde farmakolojik olmayan yöntemler. Hacettepe Üniversitesi Hemşirelik Fakültesi Dergisi. 2011;18(1):83-92.

18. Bagnasco A, Pezzi E, Rosa F, Fornonil L, Sasso L. Distraction techniques in children during venipuncture: an Italian experience. Journal of Preventive Medicine and Hygiene. 2012;53 (1):44-48.

19. Curtis S, Wingert A, Ali S. The Cochrane Library and procedural pain in children: An overview of reviews. Evidence $\square$ Based Child Health: A Cochrane Review Journal. 2012;7 (5):1363-1399. doi:10.1002/ebch.1864

20. Karaca TN. Acil serviste çocuklarda damar yolu açma işlemine yönelik oluşan korku ve anksiyete üzerine müzikli-hareketli oyuncakların etkisi. Tokat Gaziosmanpaşa Üniversitesi Sağlık Bilimleri Enstitüsü Acil Tıp Hemşireliği Ana Bilim Dalı, Yüksek Lisans Tezi. Tokat, Türkiye. 2019.

21. Erbay E. Çocuklarda periferik damar yolu açma girişimi sırasında yapılan dikkati dağıtma tekniğinin ağrıyı azaltmaya etkisi. Bülent Ecevit Üniversitesi Sağlık Bilimleri Enstitüsü Çocuk Sağlığı ve Hastalıkları Ana Bilim Dalı, Yüksek Lisans Tezi. Zonguldak, Türkiye. 2016.
22. Nguyen TN, Nilsson $\mathrm{S}$, Hellstrom AL, Bengtson A. Music therapy to reduce pain and anxiety in children with cancer undergoing lumbar puncture: A randomized clinical trial. J Pediatr Oncol Nurs. 2010;27(3):146-155. doi: $10.1177 / 1043454209355983$ 
Tablo 1. Çocukların tanıtıcı özelliklerin karşılaştırılması $(\mathrm{N}=60)$.

\begin{tabular}{|c|c|c|c|c|c|c|}
\hline \multirow[t]{2}{*}{ Değişkenler } & \multicolumn{2}{|c|}{$\begin{array}{c}\text { Deney Grubu } \\
\mathbf{n}=\mathbf{3 0}\end{array}$} & \multicolumn{2}{|c|}{$\begin{array}{c}\text { Kontrol Grubu } \\
\mathbf{n}=\mathbf{3 0}\end{array}$} & \multirow[t]{2}{*}{ Test } & \multirow[t]{2}{*}{ p } \\
\hline & $\mathbf{n}$ & $\%$ & $\mathbf{n}$ & $\%$ & & \\
\hline \multicolumn{7}{|l|}{ Cinsiyet } \\
\hline K1z & 14 & 46,7 & 15 & 50,0 & 0,067 & 1,000 \\
\hline Erkek & 16 & 53,3 & 15 & 50,0 & & \\
\hline \multicolumn{7}{|l|}{ Yaş } \\
\hline 5 yaş & 17 & 56,7 & 15 & 50,0 & 0,268 & 0,796 \\
\hline 6 yaş & 13 & 43,3 & 15 & 50,0 & & \\
\hline
\end{tabular}

Ki kare testi, Bağımsız grup t testi $p<0,01$ 
Tablo 2. Grup içi ve gruplararası $\mathrm{SpO}_{2}$ değer ortalamalarının karşılaştırılması $(\mathrm{N}=60)$.

\begin{tabular}{|c|c|c|c|}
\hline \multirow{3}{*}{ Ölçümler } & \multicolumn{2}{|c|}{$\mathrm{SpO}_{2}$ Değerleri } & \\
\hline & $\begin{array}{c}\begin{array}{c}\text { Deney Grubu } \\
\mathbf{n}=\mathbf{3 0}\end{array} \\
\end{array}$ & $\begin{array}{c}\text { Kontrol Grubu } \\
\mathbf{n}=\mathbf{3 0}\end{array}$ & \\
\hline & Ort \pm ss & Ort \pm ss & $* *$ Test / p \\
\hline İşlem öncesi ${ }^{1}$ & $96,87 \pm 0,900$ & $96,90 \pm 0,995$ & $-0,136 / 0,892$ \\
\hline İşlemden 1 dk sonra $^{2}$ & $97,23 \pm 0,774$ & $98,03 \pm 0,669$ & $-4,284 / \mathbf{0 , 0 0 0}$ \\
\hline İşlemden 5 dk. sonra $^{3}$ & $97,20 \pm 0,761$ & $97,27 \pm 0,980$ & $-0,294 / 0,770$ \\
\hline${ }^{*}$ Test $/ \mathbf{p}$ & $2,606 / 0,092$ & $\begin{array}{c}22,156 / \mathbf{0 , 0 0 0} \\
2>1,3\end{array}$ & \\
\hline
\end{tabular}

*Tekrarlı Ölçümler testi; Bonferroni testi; ** Bă̆ımsız grup t testi $p<0,01$ 
Tablo 3. Grupların ÇEGÖ puan ortalama değerlerinin karşılaştırılması $(\mathrm{N}=60)$.

\begin{tabular}{|l|c|c|c|}
\hline \multirow{4}{*}{ Ölçümler } & \multicolumn{2}{|c|}{ ÇEGÖ Puanları } & \multirow{3}{*}{} \\
\cline { 2 - 3 } & Deney Grubu & Kontrol Grubu & \\
& $\mathbf{n = 3 0}$ & $\mathbf{n = 3 0}$ & \\
\cline { 2 - 3 } & $\mathbf{O r t .} \pm \mathbf{s s}$ & Ort. $\pm \mathbf{s s}$ & $*$ Test $/ \mathbf{p}$ \\
\hline ÇEGÖ & $7,57 \pm 2,300$ & $16,50 \pm 1,225$ & $-18,780 / \mathbf{0 , 0 0 0}$ \\
\hline
\end{tabular}

**Bă̆ımsız grup t testi $\mathrm{p}<0,01 ;$ ÇEGÖ: Çocuklarda Emosyonel Göstergeler Ölçeği 


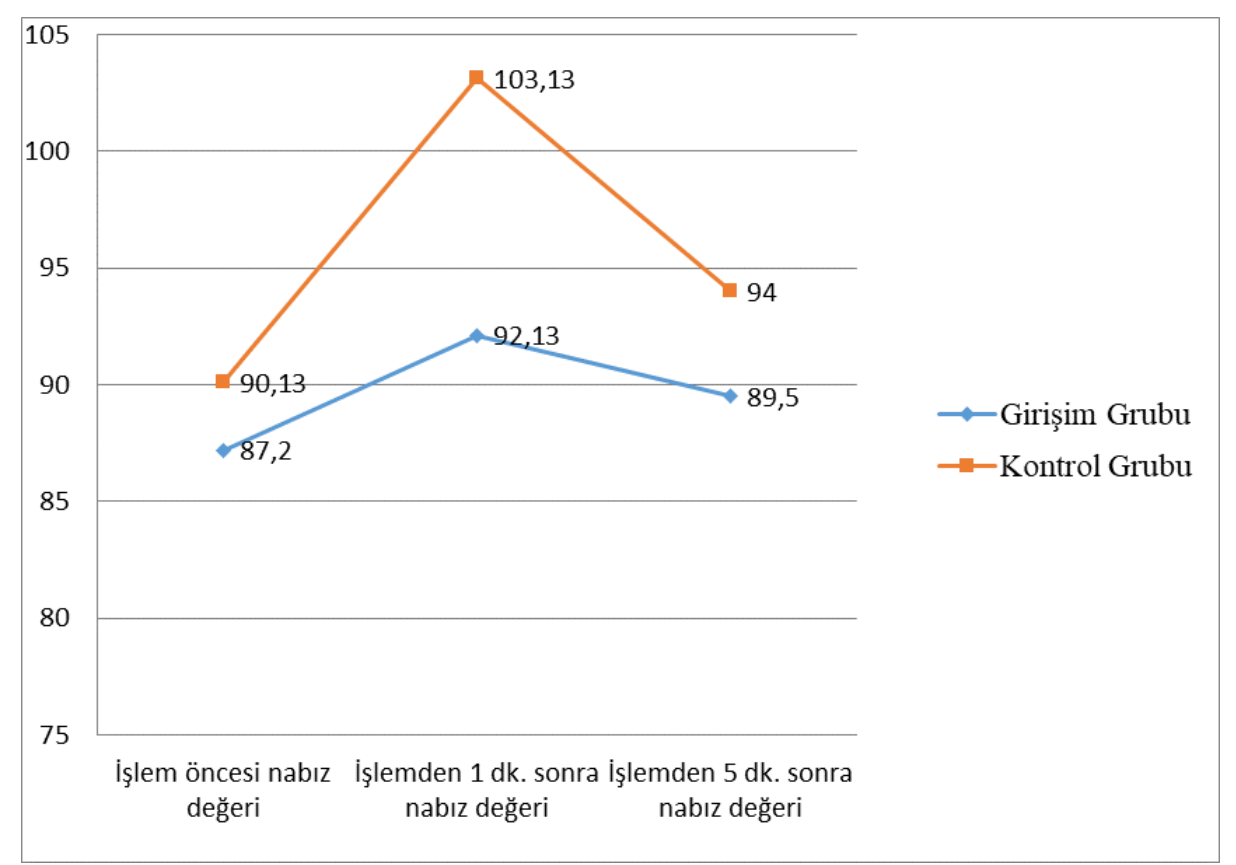

Şekil 1. Grupların nabız değeri ortalamalarının karşılaştırılması. 


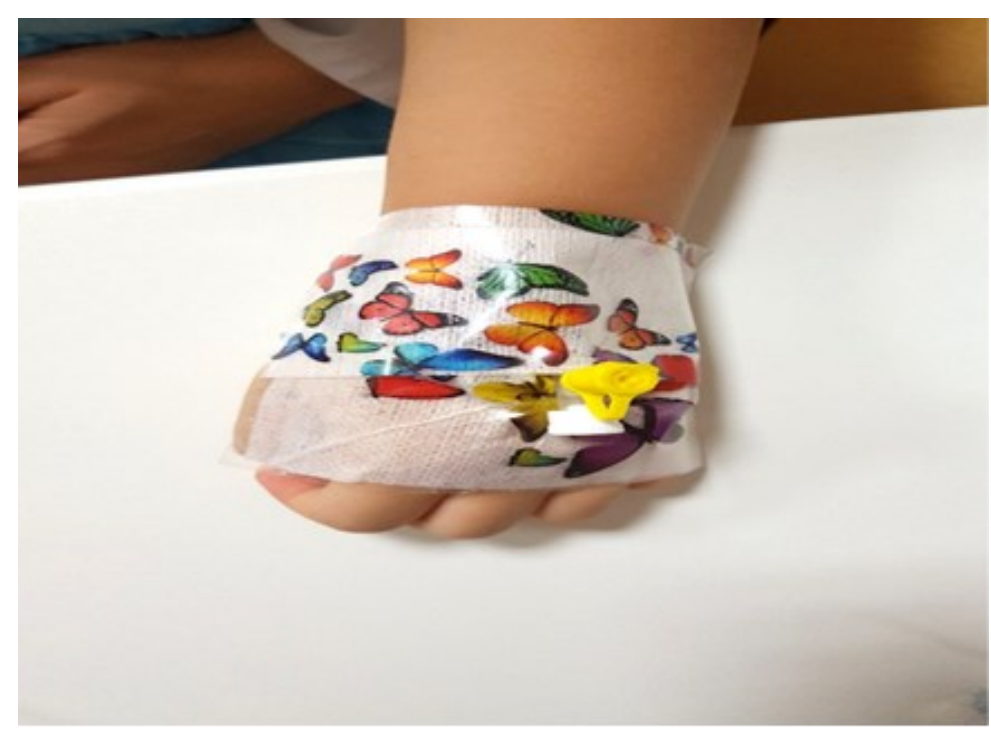

Resim 1. Desenli tespit malzemesi. 